\title{
ACROSS 20 YEARS: \\ A BIBLIOMETRIC ANALYSIS OF THE JOURNAL'S PUBLICATION OUTPUT BETWEEN 2000 AND 2020
}

\section{Krisztina Károly, ${ }^{1}$ Bea Winkler, ${ }^{2}$ Péter Kiszl ${ }^{3}$}

\author{
${ }^{1}$ School of English and American Studies, Faculty of Humanities, \\ Eötvös Loránd University, H-1088 Budapest, Rákóczi út 5. Hungary \\ E-mail: karoly.krisztina@btk.elte.hu \\ ${ }^{2}$ Hutÿra Ferenc Library, Archives and Museum, \\ University of Veterinary Medicine \\ Budapest, H-1078 Budapest, István u. 2. Hungary \\ E-mail: winkler.bea@univet.hu \\ Corresponding author: \\ ${ }^{3}$ Institute of Library and Information Science, Faculty of Humanities, \\ Eötvös Loránd University, H-1088 Budapest, Múzeum krt. 6-8. Hungary \\ Phone: +3614116567 \\ E-mail: kiszl.peter@btk.elte.hu
}

\begin{abstract}
This article offers an overview of the birth and the publication output of Across Languages and Cultures: A Multidisciplinary Journal for Translation and Interpreting Studies spanning the period between 2000 and the present day. It presents the circumstances and the aims of its creation and, based on the results of a thorough bibliometric analysis, it reveals how the journal has evolved into a Q1 international journal of Translation Studies through publishing individual as well as collaborative research conducted internationally. The analyses present the activity of the journal dominantly (but not exclusively) in figures, relating to the number and the lengths of the articles it publishes, its authorship, the countries where its authors work and its citations. The second part of the study reveals the main focuses, themes and languages of inquiry as reflected by the most frequently used words and expressions in the titles, abstracts and the lists of keywords of the articles. The paper ends by demonstrating the ways in which the journal has contributed to furthering and shaping translation research in Hungary, Europe and worldwide.
\end{abstract}

Keywords: bibliometric analysis, Translation Studies, discipline, publication output, impact 


\section{INTRODUCTION}

By the year 2000, the global spread of the scientific study of translation had become obvious, and so had the proliferation of national and international journals devoted to translation and interpreting, documenting the dynamic evolution of the field. Babel, META, Perspectives, Target, The Translator, Interpreting Newsletter, just to name but a few of these journals, had already been in full vigour. John Benjamins Publishing Company had also launched its Benjamins Translation Library series, with 40 volumes published till 2000, and altogether 154 volumes since 1994 till today. By 2000, Translation Studies (TS) had published its own encyclopaedia (Baker, M. (ed.) 1998. Encyclopedia of Translation Studies. London: Routledge.) and dictionary of terms (Shuttleworth, M., Cowie, M. 1997. Dictionary of Translation Studies. Manchester: St. Jerome.). TS, as an academic discipline, was already put on the map.

With translation and interpreting playing a crucial role in Hungary's accession to the European Union and having a unique potential and significance in the region, it also became evident that their scientific study has to have a designated journal of its own that is published in this part of the world. This was still a time when, although translator and interpreter training programmes at universities were on the rise, TS was not yet acknowledged in Hungary as a field of study in its own right. Despite the significance of translating and interpreting in practice, they were not yet dealt with extensively as a legitimate subject of scientific inquiry.

There was, however, a group of scholars, led by or working with Kinga Klaudy, an already internationally acknowledged figure, and the de facto founder, of the field in Hungary, who felt that the time has come for a change. She established a PhD Programme in TS within the Doctoral School of Linguistics at Eötvös Loránd University (Budapest), a Hungarian language journal in TS (Forditástudomány [Translation Studies]) as well as an English language journal, Across Languages and Cultures: A Multidisciplinary Journal for Translation and Interpreting Studies.

In what follows, the first 20 years of Across Languages and Cultures (briefly referred to as Across by the scholarly community), the first Hungarian published, English-language international journal of Translation and Interpreting Studies will be presented and surveyed to demonstrate, mainly in the light of statistics, the way in which it has evolved into a prestigious Q1 journal of the discipline and contributed to TS at large. 


\section{THE BIRTH OF ACROSS: CONTEXT AND PLAYERS}

Across was founded in 1999 by Kinga Klaudy as its editor-in-chief, together with Anikó Sohár as consulting editor and Krisztina Károly as managing editor. In 2004, Pál Heltai took over as consulting editor. By founding the journal Kinga Klaudy's main aim was to put Hungarian TS on the map and to provide a peerreviewed forum of publication in Central Europe that publishes quality research in the field "across languages and cultures", ranging from the Americas, through Europe, to the Far East. After the change of regime in Hungary, time was ripe to integrate research conducted in the region into the international research community and create a bridge in scholarly communication between the East and West.

Kinga Klaudy also contacted a publisher, Akadémiai Kiadó, an internationally acknowledged publishing house, which is one of Hungary's most prestigious publishers of scientific monographs and journals. It was originally founded by the Hungarian Academy of Sciences in 1828 in Budapest, and now it still operates in Budapest and its majority-owner (75\%) is the Amsterdam-based Wolters Kluwer publishing conglomerate. Its branch dealing with the publication of journals is AKJournals.

The leadership of Akadémiai Kiadó expressed genuine interest in launching and managing the new international journal. Besides Across, since 2000 Akadémiai Kiadó has come to publish over 60 peer-reviewed international journals in a wide variety of disciplines, ranging from earth sciences, chemistry, mathematics through law, sociology, psychology, literature to linguistics, art history, oriental studies, etc. All of these journals are indexed in Scopus, and many of them are indexed in the Science Citation Index or in the most important field-specific databases (i.e., Medline/Pubmed, Chemical Abstracts, Biological Abstracts, BIOSIS Previews, etc.). The overall citation of the journals has been increasing annually since 2005 .

\section{ACROSS EVOLVING INTO AN INTERNATIONAL Q1 JOURNAL}

\subsection{Publishing Policy: Quality and International Relevance}

Across publishes one volume of two issues annually in English, its first issues were published in 2000. With the leadership and staff of Akadémiai Kiadó, the editors aspired to create a truly international and quality journal in Translation and Interpreting Studies: the only policy formed as to what would be desirable to publish was that it should be high quality work, with relevance for the international community of researchers in translation and interpreting.

Across Languages and Cultures 21 (2) (2020) 
Since its foundation it has thus evolved into a recognized international journal, where not only many of the best known representatives of Translation and Interpreting Studies publish their work on a regular basis, but also young scholars and $\mathrm{PhD}$ students from all over the world gain ground. The Impact Factor (2018) of Across Languages and Cultures has grown to 1.16, its Linguistics and Language SJR Quartile Score (2019) is Q1, its Language and Linguistics SJR Quartile Score (2019) is Q1, its Scimago Journal Rank (2019) is 0.648 and its SJR Hirsch-Index (2019) is 13. It is indexed and abstracted in Arts \& Humanities Citation Index, Linguistics Abstracts, Linguistics and Language Behaviour Abstracts, Translation Studies Abstracts, SCI-EXPANDED and Social Sciences Citation Index. Therefore, it may be argued with considerable confidence that Across has made a considerable contribution to the fields of Translation and Interpreting Studies as well as to the education of researchers in the discipline.

Across publishes papers only in English, as its role as the lingua franca of academic/research communication is unquestionable. Still, Across has not just regional/European circulation and embedding. Ever since its foundation, it has worked with an international editorial and advisory board so that as many countries and continents as well as institutions (with translation training programmes and research) are represented as possible. The members of the Editorial Board are Andrew Chesterman (Finland), Zuzana Jettmarová (Czech Republic), Anthony Pym (Australia), Mary Snell-Hornby (Austria) and Sonja Tirkkonen-Condit (Finland). The members of the Advisory Board are Mona Baker (UK), Gloria Corpas Pastor (Spain), Rodica Dimitriu (Rumania), Cay Dollerup (Denmark), Birgitta Englund Dimitrova (Sweden), Henrik Gottlieb (Denmark), Sylvia Kalina (Germany), Danuta Kierzkowska (Poland), Donald Kiraly (Germany), Haidee Kotze (Netherlands), Ingrid Kurz (Austria), Sara Laviosa (Italy), Christiane Nord (Germany), Gábor Prószéky (Hungary), Alessandra Riccardi (Italy), Edina Robin (Hungary), Myriam Salama-Carr (UK), Anikó Sohár (Hungary), Margherita Ulrich (Italy) and Albert Vermes (Hungary). The editors are truly grateful for their invaluable work.

The members of these boards aid the editors in maintaining the standards of the journal and also take a decisive role in refereeing the papers submitted to be considered for publication. However, due to the extremely large number of submissions, they are not the only reviewers of the journal: it also works with many other scholars who are experts in the different subfields of the discipline, active in various parts of the world. Across has a two-level review procedure: first the papers are submitted to pre-screening to see to what extent they match the aims and the scope of the journal and, if they do, they are submitted to a double blind review procedure. 
As for its thematic focuses, Across Languages and Cultures has a wide scope, inviting publications relating to both concepts in the title: languages and cultures. In its orientation, it approaches translation (be it literary or non-literary) from the point of view of translation theory, therefore it belongs to TS and not Literary Studies. Individual (empirical or theoretical) papers published represent many of the topical issues and special fields of translation and interpreting, such as advertising, news translation, multimedia/audiovisual translation, plays, religious texts, cross-cultural aspects of translation, the role of metaphors or ideology, translation/interpreting processes, translation/interpreting competences, specialized translator training, translation universals, corpora in translation/interpreting, translation in the EU, etc. (for more on this see section 3.3). It has also published a number of thematic issues (e.g., on the translation of hybrid texts, the process of translation, corpus-based TS, methods of news translation).

To capture as many aspects as possible and to record the main events and milestones of this inter- and multidisciplinary field of study, the journal also publishes book reviews and conference reports. Occasionally, interviews have also appeared in it with some of the emblematic figures of field (e.g., Nida, Toury, Vermeer, Newmark, Wilss, Tirkkonen-Condit, Chesterman).

\subsection{The State of the Art in Figures: Article Length, Authorship, Countries and Citations}

This section presents the results of a thorough quantitative analysis of the papers and the authors of the journal, together with some data on the international embedding and impact of Across (a similar analysis of the first 20 years of Target is available by Toury, 2009). From the point of view of the methodology of the investigation, it is important to note that the findings described here are the outcomes of an interdisciplinary research project. The authors of this study work in two different areas, namely Library and Information Science and TS, and have pursued a special approach to be able to offer a bibliometric analysis of the publication/scientific output of the journal on the one hand, and a qualitative interpretation of the findings on the other, to demonstrate the relevance of the statistics for TS. Bibliometric analysis aims to evaluate the importance and the impact of publications (e.g., books, articles) published in a given period of time, based on a thorough database search of electronically available data. In the case of Across, it was data from Scopus as of 2007, WoS as of 2008, and manual collection of data from the publisher's website before these times. It is generally used to assess the scientific quality of journals and authors, as well as to reveal, 
on the basis of quantitative indicators, for example their evolution over time, number of citations, most prolific authors, institutions, most popular themes, i.e., publication trends. Such information form, among others, the bases of scientometrics too, used so widely nowadays. The statistical analyses of the information were conducted using MS Excel and SPSS, the figures visualizing the data have been produced by MS Excel and VOSviewer.

As for the presentation of the data, in what follows, a detailed analysis of the research articles will be provided (unless otherwise indicated). The analyses cover four-year time spans and thus provide data for five distinct periods of time within the 20 years: two dating back to the time before the journal was first refereed in the WoS in $2008(2000-2003 ; 2004-2007)$ and three relating to the time afterwards (2008-2011; 2012-2015; 2016-2019). Each time span (of four years) includes approximately 50 papers.

In the past 20 years, Across has published 348 papers altogether, including 257 research articles (amounting to $3 / 4$ of the total), 13 interviews, 20 conference reports and 58 book reviews. This means an average of 12 research articles annually (Figure 1).

The average length of the articles in number of pages is 19 (median: 19). Table 1 shows how the average length of papers has changed over time, broken down into the five time spans mentioned above. As the figures indicate, the average length of the articles published has increased gradually from 15.86 pages at the outset to 21.02 for more recently. This is an interesting outcome, as it does not harmonize fully with the editorial policy concerning the length of the sub-

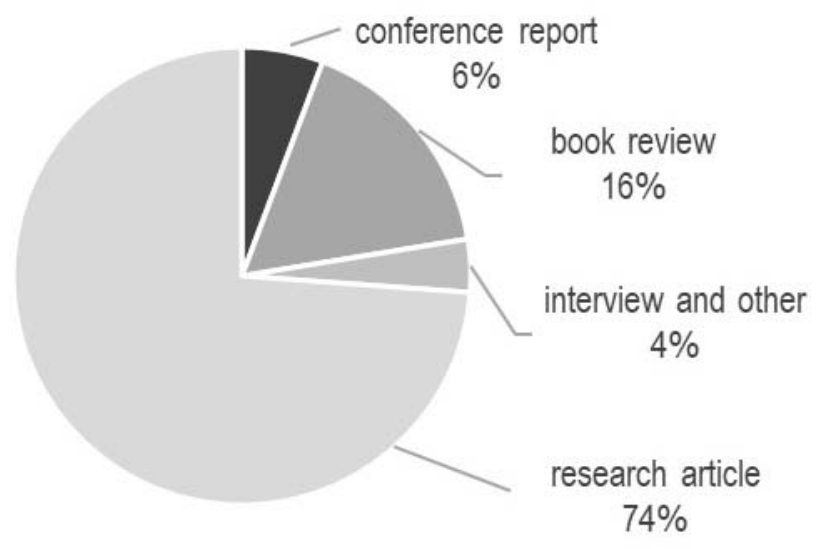

Figure 1

The ratio of papers published in the 20 volumes $(n=348)$

Across Languages and Cultures 21 (2) (2020) 
missions, which has also changed over time: at the outset (1999-2001) it was between 3000-5000 words, in 2003 it was raised to 5000-10,000 words, and the current guidelines (set in 2011) stipulate that submissions should be between 5000-7000 words. Even though the maximum length was decreased in 2011 (from 10,000 to 7000 words), the average length of the articles has increased: from 19.77 (in 2011) to 20.37 (2012-2015) and 21.02 (2016-2019).

\section{Table 1}

Average length of research articles published in the 20 volumes

\begin{tabular}{l|c}
\hline Years & $\begin{array}{c}\text { Average length of research } \\
\text { articles (in pages) }\end{array}$ \\
\hline $2000-2003$ & 15.86 \\
\hline $2004-2007$ & 18.99 \\
\hline $2008-2011$ & 19.77 \\
\hline $2012-2015$ & 20.37 \\
\hline $2016-2019$ & 21.02 \\
\hline
\end{tabular}

The authorship of the articles is varied. As Figure 2 indicates, in the 20 volumes of the journal, $72 \%$ of the research articles are single authored, $20 \%$ has two authors and the remaining $8 \%$ has three or more authors. The highest number of authors is 10 for an article, but there is only one such paper in the journal. The average number of authors is 1.48 .

The 257 research articles have a total of 381 authors (i.e., there are so many mentions of authors), some of whom are mentioned more than once. Thus there are 309 different authors in the 20 volumes. The authors getting published in

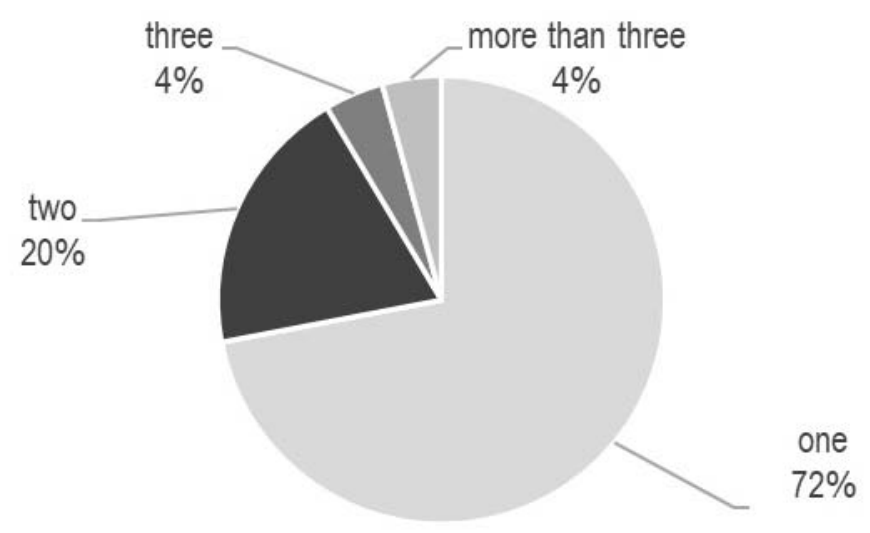

Figure 2

Percentage of articles by number of authors

Across Languages and Cultures 21 (2) (2020) 
Table 2

Top authors between 2000 and 2019

\begin{tabular}{l|c}
\hline Name & Number of articles \\
\hline Pym, Anthony & 8 \\
\hline Tirkkonen-Condit, Sonja & 7 \\
\hline Valdeón, Roberto A. & 5 \\
\hline Schäffner, Christina & 4 \\
\hline Adab, Beverly & 3 \\
\hline Kruger, Haidee & 3 \\
\hline Perego, Elisa & 3 \\
\hline Remael, Aline & 3 \\
\hline Sutter, Gert De & 3 \\
\hline Zauberga, Ieva & 3 \\
\hline
\end{tabular}

highest frequency (in order of frequency) are Anthony Pym (with 8 articles published), Sonja Tirkkonen-Condit (7), Roberto A. Valdeón (5) and Christina Schäffner (4). In addition, there are six more so-called "top authors" with three articles each (Figure 2).

The affiliations of the authors show a very diverse picture (as based on their affiliations at the time their article was actually published). As many as $99.7 \%$ of them name at least one institution (country) as their affiliation. Multiple affiliations, on the other hand, appear for merely five authors. In such cases, the first affiliation mentioned has been included in the analysis. Authors have indicated 44 distinct countries altogether in the affiliations. Table 3 enumerates the countries from which at least 10 authors have published papers in the journal. As the numbers show, the highest number of authors originate from Spain (49), which is followed by Belgium (39), Finland (32), the United Kingdom (27), Poland (22), Hungary (18), Germany (17) and Italy (14). The first non-European country in the list is the United States of America with 13 authors. The remaining places are occupied by countries in very different parts of the world: Australia, Austria and China (with 12 authors), Canada (11) and, finally, Denmark and Hong Kong (10).

Being a European journal by origin, it is also interesting to see to what extent it publishes the work of European researchers and what trends may be observed in this respect in the past 20 years. Figure 3 shows how many articles were written by authors with a non-European, or not only European affiliation (referred to briefly as non-European). Articles with at least one author with a non-European affiliation are categorized as non-European. Results indicate that $A$ cross does not restrict itself to the publication of European research exclusively: in the life of the journal there were only two years (2000 and 2003) when only European authors' research was published in it. Later on, the year 2013 marked a signifi- 
Table 3

Countries with which the majority of the authors are affiliated

\begin{tabular}{l|c}
\hline Country & Number of authors \\
\hline Spain & 49 \\
\hline Belgium & 39 \\
\hline Finland & 32 \\
\hline UK & 27 \\
\hline Poland & 22 \\
\hline Hungary & 18 \\
\hline Germany & 17 \\
\hline Italy & 14 \\
\hline USA & 13 \\
\hline Australia & 12 \\
\hline Austria & 12 \\
\hline China & 12 \\
\hline Canada & 11 \\
\hline Denmark & 10 \\
\hline Hong Kong & 10 \\
\hline
\end{tabular}

cant change of ratio: from then on, a larger number of articles published have been authored by not (or not merely) European scholars than by European ones. Non-European authors represent almost all of the continents of the world, namely Africa, America, Asia, Australia.

Articles without European authors were also investigated in the five groups created based on the four-year time spans. For the sake of comparison, the number of papers published by merely European authors is also indicated (Figure 4).

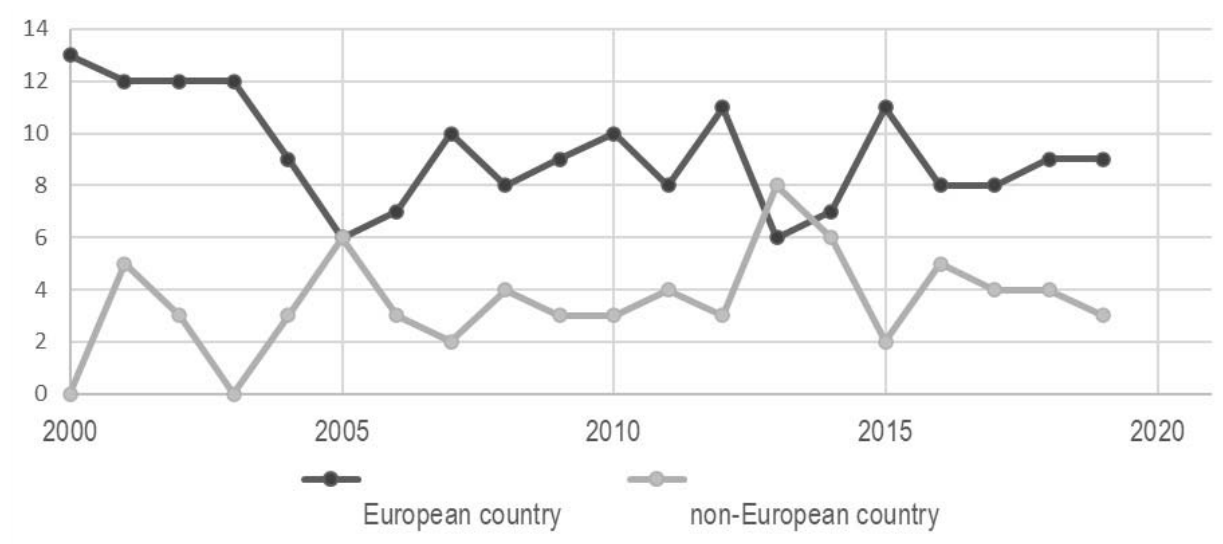

Figure 3

Articles with European and non-European affiliations in the different years

Across Languages and Cultures 21 (2) (2020) 


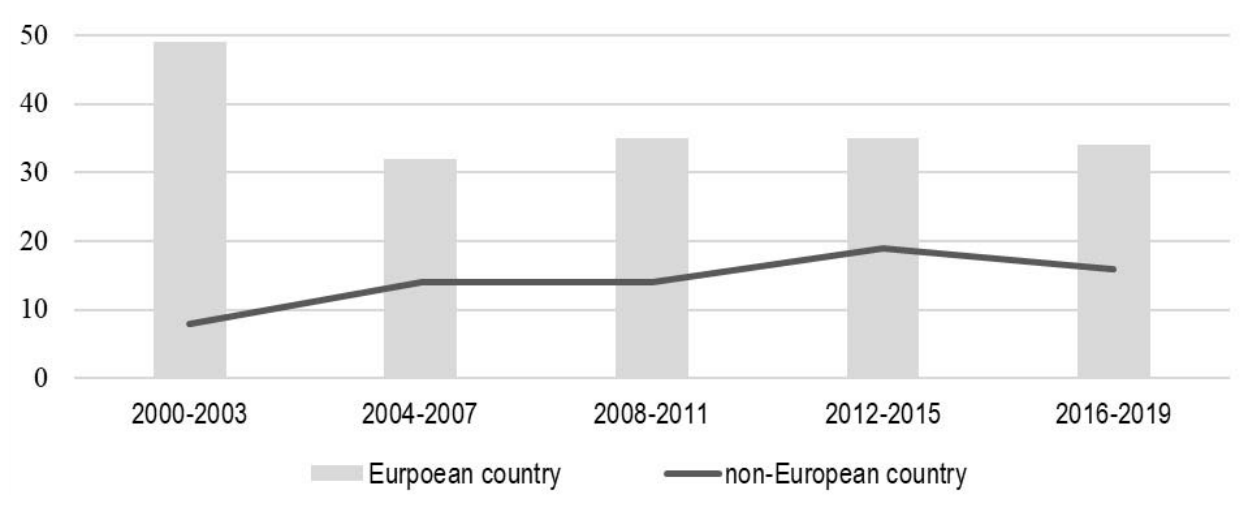

Figure 4

Number of articles with European affiliations in the five different time spans

Figure 4 demonstrates the change in time across the five periods: the first period (2000-2003) seems to differ considerably from later ones with a higher ratio of articles by (only) European authors. With time, this tendency changes, and an increase can be observed in the number of papers written by not (only) European researchers.

The quantitative analysis of the articles also shows that international cooperation plays a crucial role in the publication output of the journal. The figures reported on so far demonstrate that the journal works with an international community of authors. As many as 22 articles (amounting to almost $8.5 \%$ of the total) are produced as a result of international cooperation. From the altogether 44 countries that are represented through authors in the journal (based on their affiliations at the time of the actual publication of their article), about half ( 24 countries) are represented by co-authors in these papers. The 22 papers are authored by a total of 70 scholars, which means that, in the case of publications produced in international cooperation, the average number of authors publishing a study is 3.18. This is more than twice as high as the average number of authors publishing in the journal generally (1.48), i.e., when all of the research articles published are taken into account.

Table 4 shows how many times the various countries have been represented by co-authors working in international cooperation. Of the 24 states, two-thirds are European and one-third is non-European. As for the authors, $75 \%$ of them indicated a European country in their affiliation and $25 \%$ of them work outside of Europe. The countries represented highest are Poland and the United Kingdom (each with 8 occurrences), Australia and Belgium (6), and Spain (5). 
Table 4

Number of co-authors representing different countries

\begin{tabular}{l|c} 
Country & Occurrences \\
\hline Poland & 8 \\
\hline UK & 8 \\
\hline Australia & 6 \\
\hline Belgium & 6 \\
\hline Spain & 5 \\
\hline Switzerland & 4 \\
\hline Denmark & 3 \\
\hline Estonia & 3 \\
\hline Canada & 2 \\
\hline China & 2 \\
\hline Finland & 2 \\
\hline France & 2 \\
\hline Germany & 2 \\
\hline Hungary & 2 \\
\hline Italy & 2 \\
\hline Japan & 2 \\
\hline Netherlands & 2 \\
\hline South Africa & 2 \\
\hline USA & 2 \\
\hline Bulgaria & 1 \\
\hline Ireland & 1 \\
\hline Slovenia & 1 \\
\hline Taiwan & 1 \\
\hline Turkey & 1 \\
\hline &
\end{tabular}

Although international collaboration within articles has been present from the outset, its number has increased considerably in the past 4-8 years (20122019 ; Figure 5). In the first four-year period after the launch of the journal (20002003), only one such paper was published, in the next four years (2004-2007) two, and then (between 2008-2011) one such article again. However, from the altogether 54 articles published between 2012 and 2015, the authors of five articles were from at least two different countries and, from the 50 articles published during the period of 2016 and 2019, the authors of as many as 13 papers originated from distinct countries.

The international impact of Across may also be seen in its citation indices. It has been indexed in the Web of Science (WoS) since 2008 and by Scopus since 2007. Therefore these two databases form the basis of the citation analysis presented below. From the 208 articles included in the WoS Core Collection, more than half (112 articles) are cited. From the 184 documents of Scopus 184, 134 are 


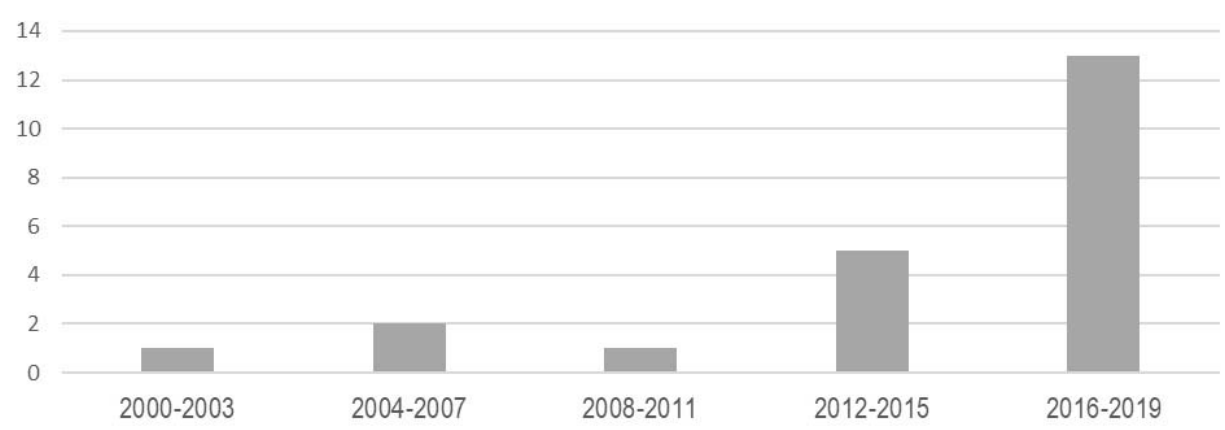

Figure 5

Number of articles published in international collaboration in the five periods

Table 5

The three most often cited articles in the first 20 years

\begin{tabular}{l|c|c|c}
\hline \multirow{2}{*}{ Authors/Title } & \multirow{2}{*}{ Year } & \multicolumn{2}{|c}{ Cites } \\
\cline { 3 - 4 } & & WoS & Scopus \\
\hline $\begin{array}{l}\text { Becher, V.: Abandoning the notion of "translation-inherent" } \\
\text { explicitation: Against a dogma of translation studies }\end{array}$ & 2010 & 53 & 55 \\
\hline $\begin{array}{l}\text { Beeby, A., Fernandez, M., Fox, O., Albir, A. H., Kozlova, I., } \\
\text { Kuznik, A., Neunzig, W., Rodriguez, P., Romero, L., Wimmer, }\end{array}$ & 2009 & 50 & 65 \\
$\begin{array}{l}\text { S.: Results of the validation of the PACTE translation } \\
\text { competence model: Acceptability and decision making }\end{array}$ & & & \\
\hline $\begin{array}{l}\text { Göpferich, S., Jääskeläinen, R.: Process research into } \\
\text { the development of translation competence: Where are we, } \\
\text { and where do we need to go? }\end{array}$ & 2009 & 44 & 51 \\
\hline
\end{tabular}

cited at least once. Table 5 shows, based on data from WoS and Scopus, the three articles with the highest (over 50) citation indices, namely by Becher (2010) on explicitation as a translation universal and by Beeby et al. (2009) and Göpferich and Jääskeläinen (2009) on particular conceptual and methodological aspects of research on translation competence.

\subsection{The State of the Art in Contents: A Word-Based Analysis of Focuses and Themes}

To reveal the dominant disciplinary (theoretical and methodological) orientations and thematic focuses of the papers published in Across in its first 20 years, a frequency analysis was conducted of the words and expressions occurring Across Languages and Cultures 21 (2) (2020) 
in the titles, the abstracts and the lists of keywords of the 257 research articles published.

As for the methods of investigation, as the first step of the analysis, a word-level analysis is conducted. This means that even if words occur as parts of multi-word expressions, they are counted separately (as independent words). The so-called "stop words" (i.e., functional/technical words such as paper, study, case, report), on the other hand, do not form part of the analysis, as they do not influence the contents directly. The only investigation where these words have also been taken into account is the analysis of the titles to see if they provide information on the approach pursued in the paper. Secondly, two-word expressions are also explored. The titles, abstracts and the keywords have been selected to form the basis of the analyses as these sections play a crucial role in defining/reflecting the contents and the approach of the research reported on. Besides the orientations and the themes, the analyses highlight the languages under scrutiny as well.

A journal has a role in disseminating information on the important milestones (such as books, monographs) and events (conferences, congresses, etc.) of the field, too. Therefore, the final part of this analysis turns to the book reviews and the conference reports that have been published to shed light, on the one hand, on the publishing houses whose publications have most frequently been reviewed and, on the other hand, on the countries which hosted the majority of the conferences reported on in the various periods.

\subsubsection{Themes in top words and expressions}

Concerning the lists of keywords, Table 6 contains the words and two-word expressions occurring in the highest frequency in the 257 research articles. Not surprisingly, the most frequent word is translation, with 166 occurrences, which adds up to $9 \%$ of the total number. The words language, interpreting, corpus, cultural, theory and explicitation also appear in large quantity (16-21 occurrences). It is interesting to note that the latter (explicitation) is also the topic of the most cited article of the journal mentioned earlier in WoS and Scopus, by Becher (2010). The most frequent two-word expression is translation process (with 12 occurrences), which is followed by roughly half as many occurrences of the terms literary translation, translation studies and corpus based (7), and simultaneous interpreting, news translation and translation competence. The list reflects the two main focuses of research published in Across: translation and interpreting. Another item on the list, translation competence, as shown earlier, is the topic of the second and third most cited articles (by Beeby et al. 2009 and by Göpferich and Jääskeläinen 2009). Translation process (the most often occurring two-word 
Table 6

Frequency of words and two-word expressions in the lists of keywords

\begin{tabular}{l|c|l|c}
\hline \multicolumn{4}{|c}{ Keywords } \\
\hline Top word & $\begin{array}{c}\text { Number of } \\
\text { occurrences }\end{array}$ & $\begin{array}{l}\text { Top phrases } \\
\text { (containing 2 words) }\end{array}$ & $\begin{array}{c}\text { Number of } \\
\text { occurrences }\end{array}$ \\
\hline translation & 166 & translation process & 12 \\
\hline language & 21 & literary translation & 7 \\
\hline interpreting & 19 & translation studies & 7 \\
\hline corpus & 18 & corpus based & 7 \\
\hline cultural & 16 & simultaneous interpreting & 6 \\
\hline theory & 16 & news translation & 6 \\
\hline explicitation & 16 & translation competence & 6 \\
\hline
\end{tabular}

expression) echoes the methodological approach of Göpferich and Jääskeläinen's (2009) study, namely process research.

Table 7 displays the figures for the abstracts. The abstracts contain 45,379 single word units, $1.67 \%$ of which (with 760 occurrences altogether) is the word translation. This would amount to an even higher number (a total of altogether 1099 occurrences altogether) if the inflected and derived variants of the same word were also counted, that is, if translations with 123, translated with 111 and translators with 105 occurrences were added to 760. This is outstanding, compared to the frequency of the other often appearing words, namely language (235), text (171) and English (165). The top phrases containing two words show a similar picture: naturally, the name of the discipline (translation studies) occurs with highest frequency, which is followed by the terms translation process (42), translation competence (24) and translated language (20), as well as target based, corpus

Table 7

Frequency of occurrence of words and two-word expressions in the abstracts

\begin{tabular}{l|c|l|c}
\hline \multicolumn{4}{|c}{ Abstracts } \\
\hline Top words & $\begin{array}{c}\text { Number of } \\
\text { occurrences }\end{array}$ & $\begin{array}{l}\text { Top phrases } \\
\text { (containing 2 words) }\end{array}$ & $\begin{array}{c}\text { Number of } \\
\text { occurrences }\end{array}$ \\
\hline translation & 760 & translation studies & 76 \\
\hline language & 235 & translation process & 42 \\
\hline text & 171 & translation competence & 24 \\
\hline English & 165 & translated language & 20 \\
\hline texts & 161 & target language & 19 \\
\hline translations & 123 & corpus based & 19 \\
\hline translated & 111 & non translated & 19 \\
\hline process & 106 & hybrid text & 14 \\
\hline translators & 105 & source language & 14 \\
\hline corpus & 103 & & \\
\hline
\end{tabular}

Across Languages and Cultures 21 (2) (2020) 
Table 8

Frequency of top words in the titles

\begin{tabular}{l|c}
\hline & Titles \\
\hline Top words & Number of occurrences \\
\hline translation & 148 \\
\hline language & 22 \\
\hline texts & 16 \\
\hline translated & 16 \\
\hline corpus & 16 \\
\hline English & 16 \\
\hline explicitation & 14 \\
\hline translator & 12 \\
\hline interpreters & 12 \\
\hline
\end{tabular}

based, non translated, hybrid text and source language (14-19 occurrences). This analysis thus reinforces the thematic focuses mentioned above and also complements those with a number of other topics and approaches that also lie in the heart of research in the field (target vs. source language/culture oriented translation, translated vs. non-translated text/language, translations as hybrid texts, etc.).

The data for the analysis of the titles are shown in Table 8 . The titles of the 257 articles contain 2,860 words altogether. These words echo the thematic focuses indicated in the lists of keywords and the abstracts. Translation scores highest (with 148 occurrences), but language (22), texts, corpus, English, explicitation, translator and interpreter also occupy a strong position in the list.

Two-word phrases have also been analysed to reveal (1) in how many articles they appear and (2) how many times they appear in total (when titles, abstracts and keywords are taken together). Figure 6 demonstrates the results for the most frequently occurring technical terms. The data with larger numbers indicate the total number of occurrences for the terms: i.e., if for example a term appeared once in the title, twice in the abstract, and once in the list of keywords, then this is counted as four occurrences. The results of this analysis also show that the term translation studies is the most frequent one (97 cases), which is then followed by translation process(es) (70), target text(s) (48) and source text(s) (46). The second set of data shows the numbers reduced to occurrences in the various articles. The outcomes of this analysis indicate no change in the first two places (for translation studies and translation processes: the former appears in 60 articles, whereas the latter appears in 39). The terms source text(s) and target text(s) come next, which appear in 28 and 27 articles respectively.

Going back to the analysis of the keywords, besides investigating the words as they follow one another in the lists, it is also informative to take a focused look at the expressions and word combinations provided by the authors. Table 9 


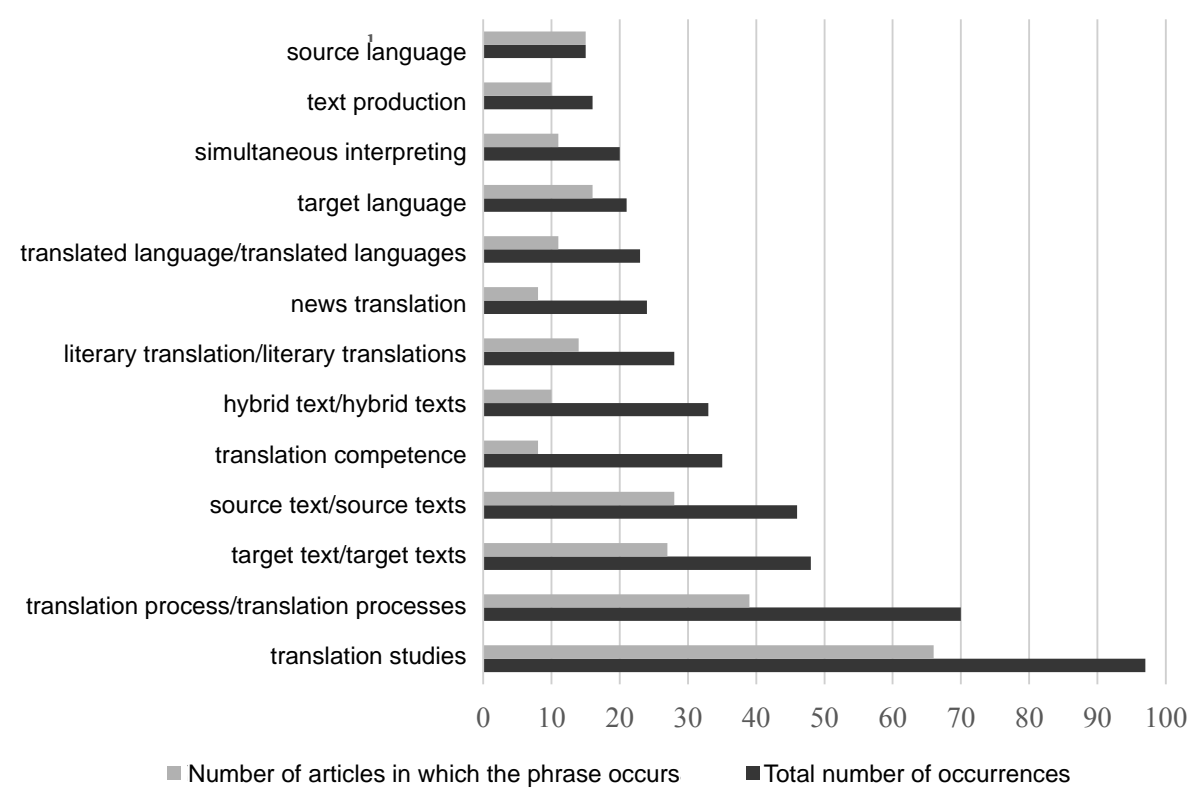

Figure 6

Two-word phrases: number of articles in which they appear and total number of occurrences in titles, abstracts and keywords

includes the data obtained by this kind of analysis in decreasing order (i.e., with the most frequently mentioned terms presented at the top). In each four-year period, there are approximately 50 publications. The table contains terms that occur at least twice in the lists of keywords (the number of occurrences is indicated in brackets next to the term). There are 40 expressions altogether which appear at least in one of the four-year periods. Results indicate that the term translation dominates all five time periods, but explicitation and literary translation also play an outstanding role (with three occurrences). The other topics alluded to involve translation in the media (by news translation, subtitling, dubbing, journalistic translation), process vs. product-oriented research (by corpora and translation process), a linguistic approach to the study of translation (e.g., by bilingual, linguistics, word-formation, morphological, pragmatics, cross-cultural communication), and several of the central concerns of translation research (e.g., translation competence, ideology, norm, rewriting, risk and risk management, reception, cultural identity, globalisation, revision, less translated languages, hybridity, translation policy).

Interestingly, keywords also combine. To illustrate this, as the journal has been refereed by WoS since 2008, Figure 7 shows the network of relations between 
Table 9

Frequent words and word combinations provided by the authors in the lists of keywords

\begin{tabular}{|c|c|c|c|c|}
\hline $2000-2003$ & 2004-2007 & 2008-2011 & 2012-2015 & 2016-2019 \\
\hline translation (9) & translation (5) & translation (7) & translation (5) & $\begin{array}{l}\text { news } \\
\text { translation (4) }\end{array}$ \\
\hline bilingual (3) & linguistics (2) & $\begin{array}{l}\text { translation } \\
\text { process (5) }\end{array}$ & explicitation (4) & subtitling (4) \\
\hline explicitation (3) & norm (2) & $\begin{array}{l}\text { translation } \\
\text { competence (3) }\end{array}$ & word-formation (3) & translation (3) \\
\hline ideology (3) & pragmatics (2) & explicitation (2) & corpora (2) & dubbing (2) \\
\hline $\begin{array}{l}\text { literary } \\
\text { translation (3) }\end{array}$ & rewriting (2) & $\begin{array}{l}\text { literal } \\
\text { translation (2) }\end{array}$ & $\begin{array}{l}\text { corpus-based } \\
\text { translation } \\
\text { studies (2) }\end{array}$ & $\begin{array}{l}\text { journalistic } \\
\text { translation (2) }\end{array}$ \\
\hline $\begin{array}{l}\text { cross-cultural } \\
\text { communication } \\
\text { (2) }\end{array}$ & $\begin{array}{l}\text { risk and risk } \\
\text { management (2) }\end{array}$ & $\begin{array}{l}\text { literary } \\
\text { translation (2) }\end{array}$ & implicitation (2) & reception (2) \\
\hline $\begin{array}{l}\text { cultural } \\
\text { identity (2) }\end{array}$ & $\begin{array}{l}\text { translated } \\
\text { Finnish (2) }\end{array}$ & $\begin{array}{l}\text { process } \\
\text { research (2) }\end{array}$ & $\begin{array}{l}\text { less translated } \\
\text { languages (2) }\end{array}$ & $\begin{array}{l}\text { simultaneous } \\
\text { interpreting } \\
(2) \\
\end{array}$ \\
\hline globalisation (2) & & revision (2) & $\begin{array}{l}\text { literary } \\
\text { translation (2) }\end{array}$ & \\
\hline hybridity (2) & & $\begin{array}{l}\text { translation } \\
\text { studies (2) } \\
\end{array}$ & morphological (2) & \\
\hline methodology (2) & & & problem-solving (2) & \\
\hline \multicolumn{5}{|l|}{$\begin{array}{l}\text { multilingual } \\
\text { environment (2) }\end{array}$} \\
\hline \multicolumn{5}{|l|}{ postcolonial (2) } \\
\hline \multicolumn{5}{|l|}{$\begin{array}{l}\text { think-aloud } \\
\text { method (2) }\end{array}$} \\
\hline \multicolumn{5}{|l|}{$\begin{array}{l}\text { translation } \\
\text { policy (2) }\end{array}$} \\
\hline usability (2) & & & & \\
\hline
\end{tabular}

the keywords of the period between 2008-2019 (based on WoS data). There are many nodes (central notions) in the figure, whose elements are related to one another as well. One of these central notions is translation, to which other nodes connect, such as explicitation, translation competence and language. Explicitation is a significant node too, which, besides translation, is also connected with language. News translation is linked to English and corpora. In the latter case, the relation between language and translation is created via corpora. This network of relations, created on the basis of the keywords, may function as a mind map, reflecting the contents of these 12 volumes of Across.

In sum, as for the main themes, the word-based frequency analyses highlight dominantly those terms that represent or relate to some of the "traditional" 


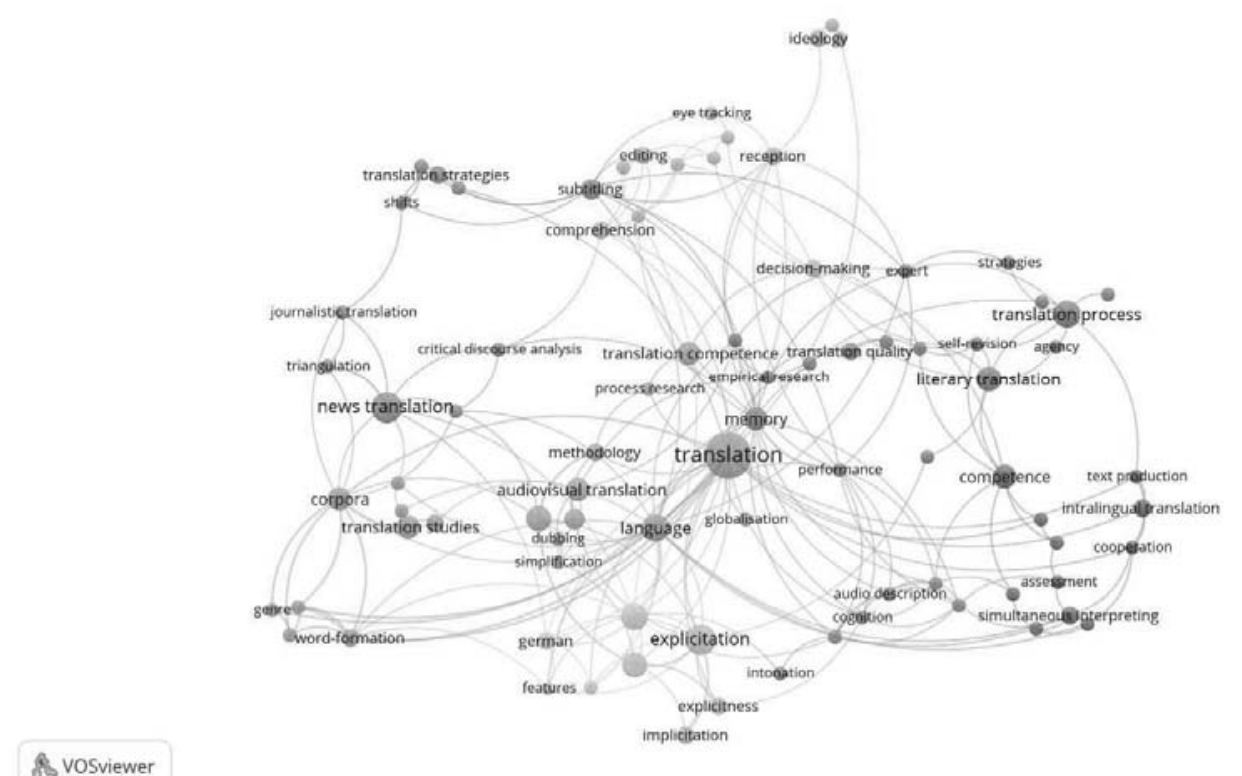

Figure 7

Network of relations between keywords (2008-2019)

(evergreen) topics of translation research: explicitation, literary translation, linguistic analysis, text production, translation strategies, translation competence, shifts, journalistic translation, inter-cultural communication, etc. However, if one takes a closer look, the changes that have affected the profession due to globalization and the rapid development of technology, the establishment of translator and interpreter training programmes in almost all continents of the world, and the development of the discipline itself (in its theories and methods) also leave their traces in the articles. Hence the occurrence of other

(1) more topical themes too among the high frequency words, such as intralingual translation, eye-tracking, audiodescription, memory, cognition, editing, hybridity, reception, agency, ideology, risk and risk management, and

(2) terms reflecting the development of the research methodological toolkit of the area, namely process research, triangulation, think-aloud method, corpus-based, etc.

These more "novel" themes neatly reflect the interdisciplinary nature of the field, where the collaboration and the communication of several areas of study (theoretical and applied linguistics, pragmatics, psycholinguistics, genre analy- 
sis, discourse analysis, sociology, communication studies, media studies, to name but a few) are needed to be able to provide adequate answers to the more and more complex questions of research.

\subsubsection{Languages investigated}

Besides the thematic focuses, the languages under scrutiny in the different articles have also been investigated based on frequency of occurrence. First, their frequency was calculated in the abstracts and, secondly, their occurrences in the articles, to reveal how many articles deal with the given languages. Results show that English is mentioned the most often (in 75 articles), which is followed by German (20), Spanish and French (17), Chinese (15) and Finnish (13). These languages appear in the abstracts of at least 10 research articles. Further languages, mentioned at least in two articles, are Italian, Arabic, Dutch, Hungarian, Polish, Greek, Turkish, Russian, Japanese, Afrikaans, Catalan and Danish. The languages which are mentioned at least in one article are, for instance, Czech, Farsi, Hebrew, Slovenian, Bulgarian.

Figure 8 demonstrates the frequency data for the languages that have been mentioned at least in six articles in the 20 years. Six articles have been defined as the limit as this number still provides sufficiently many different languages that can still be fit into a figure in a way that the results are interpretable. The frequencies are presented separately for the five time spans used earlier, too. Language

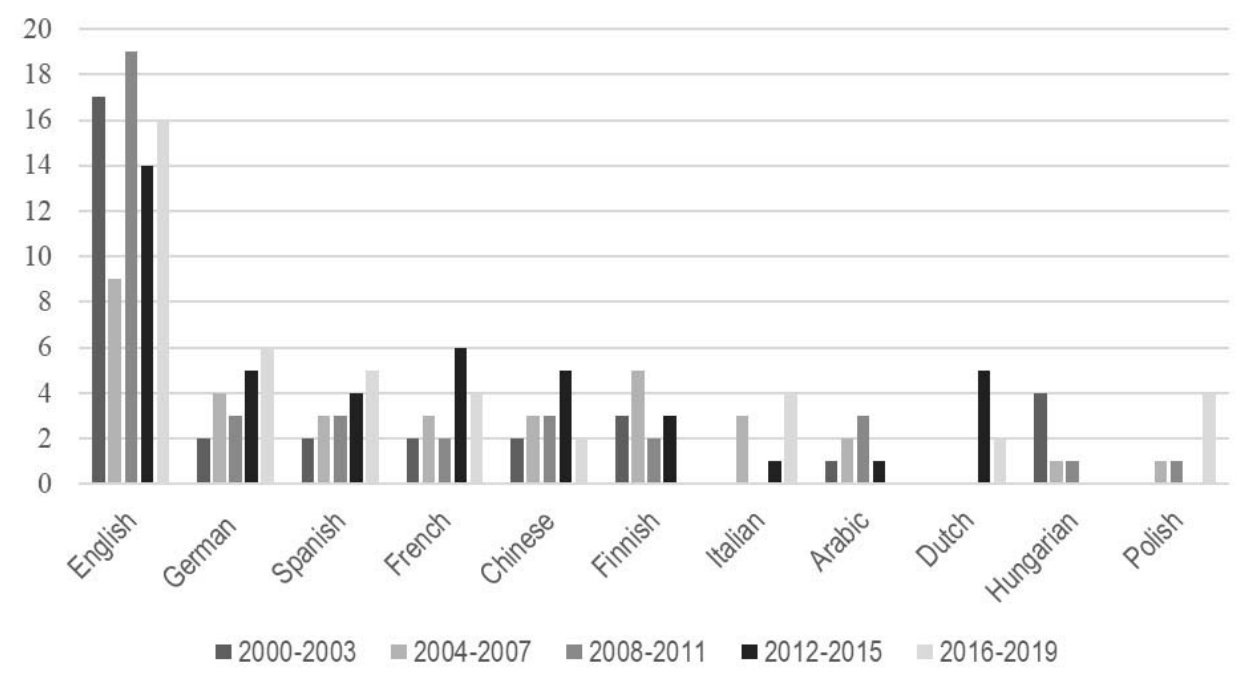

Figure 8

Languages mentioned at least in six articles in the different periods

Across Languages and Cultures 21 (2) (2020) 
pairs, unfortunately, could not be sought for in this analysis, as the various languages are mentioned in different forms (with inflectional and derivational variants and with varying punctuation; e.g., with or without hyphens), which makes their identification unreliable.

The abstracts were further analysed to see what languages are in focus in the different papers. This investigation is also based on frequency of occurrence. Altogether 33 different languages appear in the abstracts. The language occurring in highest frequency is English (with 165 mentions), then come Spanish (with 45) and German (with 32), but Arabic, Chinese, Finnish and French also occupy significant positions (between 20-30 mentions). Dutch, Greek, Hungarian, Italian, Polish and Turkish appear in lower frequency (by 10-19 mentions), and Africaans, Belgian, Bulgarian, Catalan, Caucasian languages, Croatian, Czech, Danish, Farsi, Flemish, Hebrew, Japanese, Latvian, Korean, Portuguese, Russian, Serbian, Slovenian, Swedish and Ukrainian occur less than 10 times.

\subsubsection{Book reviews}

The journal has published reviews of 84 books in these 20 years in 58 book review papers altogether. Some of these review one book, others review more. The analysis below is based on the 84 reviews. The book reviews are both critical and informative: they contain a lot of details, spread over several pages, often with references, and occasionally with a detailed presentation/discussion of particular chapters of the books or monographs.

The publishing houses represented in the highest frequency are John Benjamins (19 occurrences), St. Jerome Publishing (17) and Routledge (3). There are also other publishers that appear more than once: Narr Verlag, Multilingual Matters, Rodopi, Scholastica and Springer. Figure 9 shows the number of publishers and the number of books covered by the book reviews published in the five four-year periods of the journal.

\subsubsection{Conference reports}

Across has reported on 29 events (conferences or congresses) in its first 20 years, organized in 12 different countries of the world. These events appear in 20 "papers" (i.e., conference reports) altogether. The data presented below are based on the conferences/congresses (not the actual conference reports as papers). The results of the analysis indicate that almost $90 \%$ of the events were organized in a European country (in order of frequency): in Belgium (5 conferences), Spain (4), Finland, Germany and Italy (3), Poland, Slovenia and the United Kingdom (2) 


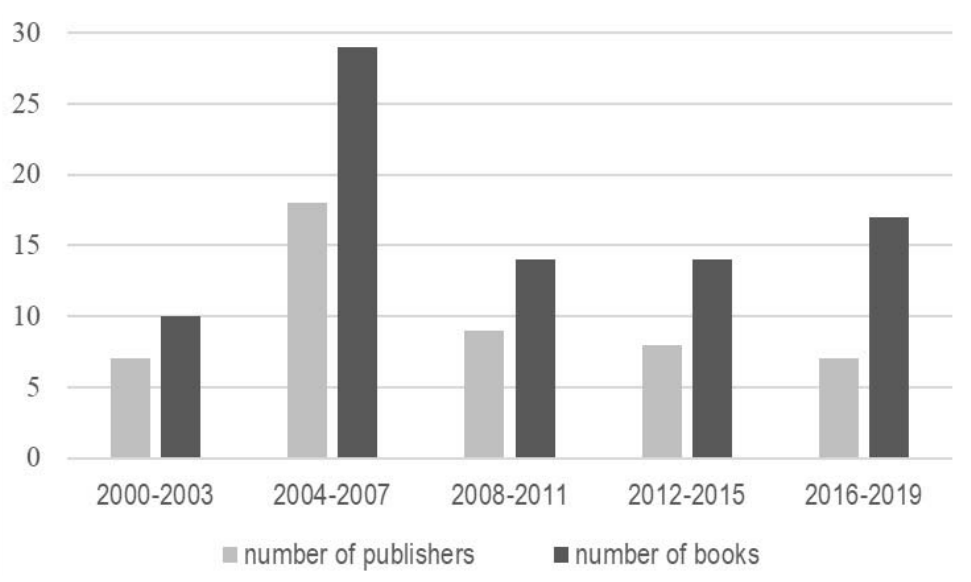

Figure 9

Number of publishers and books in the book review section

and, finally, in Hungary and Portugal (1). There are two exceptions: two conferences were organized in Asia (in China) and one in Africa (in South Africa).

Figure 10 demonstrates the results for the five four-year periods. The outcomes are surprising: countries organizing events in the early years typically do not organize conferences in later years. Another striking tendency is that after the activity of the first three periods, in the past eight years the number of conferences seems to decline.

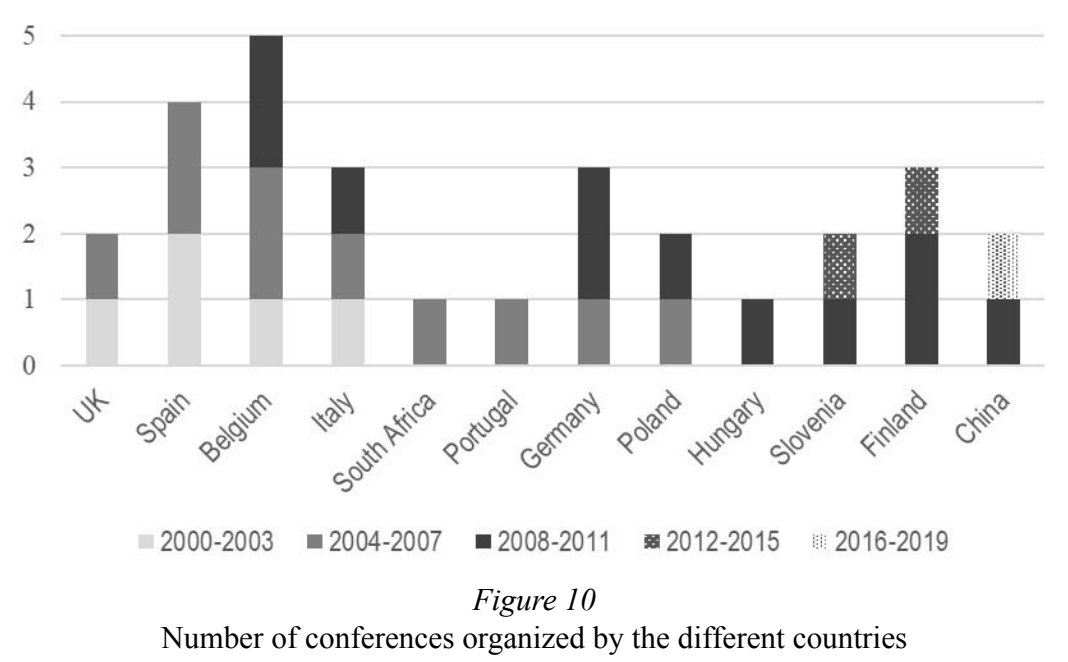

Across Languages and Cultures 21 (2) (2020) 


\section{LOOKING BACK AND LOOKING AHEAD}

\subsection{Changes Over Time}

As a result of the continuously growing number of submissions, there have been certain changes over time in the life of Across. One of these affects the publication of thematic issues. The editors have to occasionally suspend the acceptance of proposals for thematic issues due to the large number of submissions recommended for publication by the reviewers but still waiting to be published.

Also because of the large number of submissions, the review procedure has been complemented: the so-called pre-screening procedure has been introduced before the regular review process. As the work of the editors and reviewers is becoming more and more demanding, first the submissions are pre-screened for topic, relevance, research design, referencing, language use, and to see whether they are likely to generate interest. If they get past this stage, then they are submitted to the double blind peer-review system. In case of conflicting reviews, a third reader is also involved. The review procedure typically takes about 5 months and concludes by one of the following decisions: accept, accept with modification, substantially revise and resubmit, reject. If the decision is "accept with modification" or "substantially revise and resubmit", then authors are expected to respond to the reviews and enumerate the changes they have made in the revised version of their paper.

The rate of acceptance has also decreased compared to earlier times. Due to the continuously increasing number of submissions (despite the growing number of journals in the field), and because of the merely two issues per year, more and more demanding selection criteria have been introduced and thus more papers are declined or directed to other journals. Therefore, more recently, reviewers are requested to return their reviews in two months, so that authors do not lose much time in case their paper is not accepted for publication.

\subsection{Plans}

To maintain (and possibly further enhance) the quality of the journal, the editors, the editorial and the advisory boards work on ways of dealing with the problems resulting from the demands of publication. Some of the areas of possible future development include increasing the number of issues published per year. This, however, would put even more burden on the editors and the reviewers, therefore a larger editorial staff and a very clear distribution of labour would also be 
needed. It also means extra costs for the publisher. Therefore, the implementation of such a change needs careful planning both professionally and financially.

To enhance the administrative burdens of working with so many papers, like with other journals, Akadémiai Kiadó is launching an online manuscript submission and peer review system for Across, too. This electronic submission system is hoped to substantially reduce the editorial processing and reviewing times and shorten overall publication times. By using this tool, authors will be able to submit manuscripts, check on the status of their paper, read reviews and editors' comments, and communicate with the editorial office through the Internet.

\subsection{Concluding Remarks}

The bibliometric analysis presented above aimed to describe in numbers the activity of the journal Across Languages and Cultures in its first two decades. In addition, through the figures, it provides empirical evidence for a number of claims that can be made not only regarding the journal, but also concerning the way it has furthered and shaped (of course along with the other journals of the field) the study of translation and interpreting in Hungary, Europe and worldwide. In time Across has contributed to establishing TS as a field of scholarly study in Hungary too, and has put Hungarian translation research on the map, integrating it into the international research community.

Even though the statistical analyses reported on in this paper have shed light on a number of interesting and significant issues related to Across and, indirectly, to TS, what we have seen is by far not the full picture. There may be many other aspects of the activity of the journal (regional distribution, gender and age of authors, acceptance/rejection statistics, ethical problems, etc.) that might be of interest, however, either due to their confidential nature or to lack of accessibility of data, we needed to refrain from sharing these.

On the other hand, from the data gathered, it is obvious that in the past 20 years TS has grown remarkably. It has become an area of study where (1) international and intercontinental cooperation play a significant role, (2) inter- and multidisciplinary research has proliferated, (3) the research and publication activity of scholars working outside of Europe has risen drastically, (4) conducting empirical studies using meticulously designed research methods is the norm, (5) new focuses and themes of research constantly evolve (in line with the evolution of science at large) and (5) the publication output of scholars is reaching unprecedented numbers. No small feat indeed. 


\section{References}

Baker, M. (ed.) 1998. Encyclopedia of Translation Studies. London: Routledge.

Shuttleworth, M., Cowie, M. 1997. Dictionary of Translation Studies. Manchester: St. Jerome.

Toury, G. 2009. Incubation, Birth and Growth. Observations on the First 20 Years of Target. Target Vol. 21. No. 2. 189-207. DOI: 10.1075/target.21.2.00tou.

Open Access. This is an open-access article distributed under the terms of the Creative Commons Attribution 4.0 International License (https:/creativecommons.org/licenses/ by/4.0), which permits unrestricted use, distribution, and reproduction in any medium, provided the original author and source are credited, a link to the CC License is provided, and changes - if any - are indicated. (SID_1)

Across Languages and Cultures 21 (2) (2020) 